\title{
Interleukin-1 receptor-associated kinase-M suppresses systemic lupus erythematosus
}

\author{
Maciej Lech, ${ }^{1}$ Claudia Kantner, ${ }^{1}$ Onkar P Kulkarni, ${ }^{1}$ Mi Ryu, ${ }^{1}$ Ekaterina Vlasova, ${ }^{2}$ \\ Jürgen Heesemann, ${ }^{2}$ David Anz, ${ }^{3}$ Stefan Endres, ${ }^{3}$ Koichi S Kobayashi, ${ }^{4,5}$ \\ Richard A Flavell, ${ }^{4}$ Javier Martin, ${ }^{6}$ Hans-Joachim Anders ${ }^{1}$
}

- Additional tables are published online only. To view the files please visit the journal online at (http://ard.bmj.com)

${ }^{1}$ Medizinische Poliklinik, Campus Innenstadt, Klinikum der Universität München - LMU,

Munich, Germany

${ }^{2}$ Max von Pettenkofer Institute for Hygiene and Medical Microbiology, University of

Munich, Germany

${ }^{3}$ Department of Clinical

Pharmacology, University of

Munich, Munich, Germany

${ }^{4}$ Section of Immunobiology,

Howard Hughes Medical

Institute, Yale University School

of Medicine, New Haven,

Connecticut, USA

${ }^{5}$ Department of Cancer Immunology and AIDS

Dana-Farber Cancer Institute,

Boston, Massachusetts, USA

${ }^{6}$ Instituto de Parasitologia y

Biomedicina "Lopez-Neyra",

CSIC, Granada, Spain

\section{Correspondence to}

Hans-Joachim Anders,

Medizinische Poliklinik,

Universität München,

Pettenkoferstr. 8a, D-80336

München, Germany;

hjanders@med.uni-muenchen.de

$\mathrm{ML}$ and CK contributed equally

Accepted 17 July 2011

Published Online First

29 August 2011

\begin{abstract}
Objectives Interleukin-1 receptor-associated kinase (IRAK)-M suppresses Toll-like receptor (TLR)-mediated activation of innate immunity during infection. A similar role was hypothesised for IRAK-M in autoimmunity.

Methods Irak-m-deficient mice were crossed with autoimmune C57BL/6-Ipr/lpr mice and detailed phenotype analysis was performed.
\end{abstract}

Results Irak-m deficiency converted the mild autoimmune phenotype of C57BL/6-Ipr/lpr mice into a massive lymphoproliferative syndrome with lethal autoimmune lung disease and lupus nephritis. Irak-m deficiency induced a number of interferon-related genes, cytokines and plasma cell survival factors in spleen cells of these mice. Irak-m-deficient C57BL/6-Ipr/lpr mice showed expansion of autoreactive T cells, dysfunctional regulatory T cells and plasma cells which was associated with increased lupus autoantibody production. TLR7 antagonism almost completely abrogated this phenotype consistent with IRAK-M-mediated suppression of TLR7 signalling in vitro.

Conclusions These data identify a previously unknown function of IRAK-M — namely, suppression of TLR7mediated autoimmunity — and mutant IRAK-M as a previously unknown genetic risk for murine SLE.

\section{INTRODUCTION}

Autoimmunity means loss of tolerance against selfantigens by, for example, the presence of autoantibodies. Transient autoimmunity is common, but whether or not it manifests as autoimmune tissue injury depends on the signals and genetic factors that regulate the expansion of autoreactive lymphocytes. ${ }^{12}$ For example, in systemic lupus erythematosus (SLE), loss of tolerance affects ubiqitous nuclear autoantigens and can result in a spectrum of clinical manifestations ranging from mild skin rashes and arthralgia to severe inflammation of the kidney, lungs or brain. ${ }^{3}$ SLE develops when gene variants promote the exposure of nuclear particles to the immune system-for example, defects in apoptosis, in opsonisation of dying cells, in phagocytosis or in extracellular nuclease activity. ${ }^{4}$ Other genetic risk factors affect immune recognition of self-nucleic acids by Toll-like receptors (TLR), subsequent danger signalling and the production of type I interferons, ${ }^{5}$ a process that also enhances the presentation of nuclear autoantigens and the subsequent expansion of autoreactive lymphocytes. ${ }^{6} \mathrm{~A}$ third class of genetic factors promote tissue inflammation and damage. ${ }^{4}$ Combinations of genetic polymorphisms in either weak or potent susceptibility genes account for the variable disease onset and clinical manifestation patterns in human SLE. For example, a genome-wide association study in 1311 patients with SLE and 3340 control subjects identified HLA, STAT4, IRF5, BLK and ITGAMITGAX as variant genes with a particularly strong association with SLE.

Murine studies have been used to identify the relative importance of single genes for SLE. For example, potent susceptibility genes such as transforming growth factor $\beta_{1}$ (TGF- $\beta_{1}$ ), DNase 1 , Lyn, Fas or $\mathrm{C} 1 \mathrm{q}$ were identified because they were sufficient to cause lupus-like autoimmunity in the absence of additional predisposing factors. ${ }^{8-13}$ Lupus risk genes are less potent when they require a second genetic factor to trigger SLE- that is, genes such as SLE1, TLR7, TLR9 or SIGIRR. ${ }^{14-17}$ Weaker disease modifier genes such as interleukin (IL)-10 or IL-27R enhance SLE only together with other susceptibility genes, for example, being provided by the specific autoimmune genetic background of MRL mice. ${ }^{18} 19$

The interleukin-1 receptor-associated kinases (IRAK) have important roles in innate immunity because they regulate signal transduction of the IL-1R and the TLRs. For example, the MyD88 signalling pathway requires IRAK-4 to phosphorylate TRAF6, ${ }^{20}$ which is inhibited by another member of the IRAK family, IRAK-M, in cells of the monocyte/macrophage lineage. ${ }^{21} 22$ IRAK-M induction contributes to endotoxin tolerance ${ }^{21} 22$ and sepsisinduced $^{23}$ or tumour-associated immunosuppression. ${ }^{24}$ IRAK-M also limits infection-associated immunopathology ${ }^{25}$ and prevents osteoporosis by suppressing osteoclast differentiation. ${ }^{26}$ Consistent with these immunosuppressive effects, loss of function mutations in the human IRAK-M gene are associated with inappropriate immunopathology such as in asthma. ${ }^{27}$ Interestingly, genome-wide association studies located as yet unknown lupus risk factors to the IRAK-M gene locus at chromosome $12 \mathrm{p} 14 .^{7}$ We therefore hypothesised a role for IRAK-M beyond the control of microbial defence in the suppression of inadequate TLR signalling in antigen-presenting cells (APCs), a recently discovered pathomechanism of autoimmunity. ${ }^{6} \mathrm{We}$ approached this hypothesis by characterising the phenotype of Irak-m-deficient C57BL/ $6^{\mathrm{pr} / \mathrm{pr}}$ (B6 $6^{\mathrm{lp} r}$ ) mice in which the lpr mutation fosters autoantibody production and mild autoimmune tissue injury. ${ }^{8}$

\section{METHODS \\ Animal studies}

Irak-m-deficient mice were generated as previously described ${ }^{21}$ and back-crossed to the C57BL/ 6 strain 
(B6; Charles River Laboratories, Sulzbach Germany) to the F10 generation. B6 Ipr/Irak-m-/ and B6 lpr mice (Charles River) were mated to generate B6/pr/Irak-m-/+ mice which were then mated among each other to generate $\mathrm{B} 6^{\text {pr/Irak-m+/+}}$ and $\mathrm{B} 6^{\text {Ipr/Irak-m-/- }}$ mice. Littermates were used for all experimental procedures. In each individual mouse the genotype was assured by PCR. Mice were housed in groups of five in sterile filter top cages with a $12 \mathrm{~h}$ dark/light cycle and unlimited access to autoclaved food and water. Power calculations performed on the primary endpoint (the 'lupus nephritis activity index') determined a group size of 17. One cohort of mice was killed by cervical dislocation at 24 weeks of age and one cohort was followed until 52 weeks of

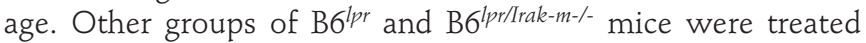
by intraperitoneal injection either with saline or with the TLR7 blocking phosphothioate oligodeoxyribonucleotide IRS 661 (5'-TGCTTGCAAGC TTGCAA-GCA-3'; TIB Molbiol, Berlin, Germany) at a dose of $40 \mu \mathrm{g}$ on alternate days from weeks 13-24 of age as described elsewhere. ${ }^{28}$ IRS 661 prevents the activation of dendritic cells and B cells of lpr mice upon exposure to TLR7 agonists, ${ }^{28} 29$ and the dose selected was previously shown to be effective in vivo. ${ }^{28}$ All experimental procedures were performed according to the German animal care and ethics legislation and had been approved by the local government authorities.

\section{In vitro experiments}

Spleen monocytes from wild-type and Irak-m-deficient mice were kept in RPMI medium with 10\% fetal calf serum and 1\% penicillin/streptomycin. $5 \times 10^{6}$ cells in 12 -well plates were stimulated for $24 \mathrm{~h}$ with the TLR4 agonist ultrapure lipopolysaccharide (LPS, $1 \mu \mathrm{g} / \mathrm{ml}$; Invitrogen, Karlsruhe, Germany), the TLR7 agonist imiquimod ( $1 \mu \mathrm{g} / \mathrm{ml}$; Sequoia Research Products Ltd, Oxford, UK) or the TLR9 agonist CpG-DNA (1 $\mu \mathrm{g} / \mathrm{ml}$; Invitrogen). Y12 and snRNP (Arotec, Wellington, New Zealand) were used in concentrations of $5 \mu \mathrm{g} / \mathrm{ml}$ and $10 \mu \mathrm{g} / \mathrm{ml}$, respectively. IL- 6 and tumour necrosis factor $\alpha$ (TNF $\alpha$ ) concentrations were determined in cell supernatants by ELISA following the manufacturer's protocols (OptEiA; BD Biosciences, Heidelberg, Germany).

\section{Flow cytometry}

Anti-mouse CD3, CD4, CD8 and CD25 (BD Pharmingen, Heidelberg, Germany) antibodies were used to detect CD3+CD4-CD8- double negative $\mathrm{T}$ cells and CD4+CD25+/ Foxp3 regulatory $\mathrm{T}$ cell (Treg) populations in the spleen. CD11c was stained to identify plasmacytoid and myeloid dendritic cells and their activation was assessed by co-staining for CD40 and MHC II (BD Pharmingen). Dendritic cell subtypes were identified using CD4 and CD8a co-stained with CD11c. Anti-mouse B220, CD21, CD23, IgD and IgM antibodies (BD Pharmingen) were used to identify $B$ cell subsets from a spleen single cell suspension. Anti-mouse $\kappa$ light chain and CD138 (BD Pharmingen) were used to identify plasma cells. F4/80, CD11b and MHC II (BD Pharmingen) were used to identify macrophage activation. Activated B cells were identified with co-staining of B220, CD19 and CD69 (BD Pharmingen) and T cell activation was identified with CD69 co-stained with T cell markers shown above. An Annexin V-FITC Apoptosis Detection Kit (BD Pharmingen) was used to identify apoptotic cells. Respective isotype antibodies were used to demonstrate specific staining of cell subpopulations. Cell counting beads (Invitrogen) were used for cell counting by fluorescence-activated cell sorting (FACS).

\section{T cell proliferation assays}

CD4+CD25+ Treg cells and CD4+CD25 $5^{\text {neg }} \mathrm{T}$ effector (Teff) cells from the spleen were purified by two-step magnetic cell sorting
(Miltenyi Biotec, Bergisch Gladbach, Germany). The remaining cells were used as APCs. CD4+CD25 neg Teff cells $\left(7.5 \times 10^{4}\right.$ cells) were activated with anti-CD3 antibody $(0.1 \mu \mathrm{g} / \mathrm{ml}$, clone $500 \mathrm{~A} 2, \mathrm{BD}$ Biosciences) in the presence of APCs $\left(2 \times 10^{4}\right.$ cells $)$ and increasing numbers of CD4+CD25+ Tregs $\left(5-40 \times 10^{3}\right.$ cells) as described previously. ${ }^{30}$ The cells were then co-cultured for 60 $h$ in the presence of BrdU (Sigma-Aldrich, Steinheim, Germany). BrdU incorporation into CD4+FoxP3 ${ }^{\text {neg }}$ Teff cells was detected by flow cytometry using a Regulatory T Cell Staining Kit (eBioscience, San Diego, California, USA). After incubation with Pacific Blue-labelled FoxP3 antibody, the cells were fixed with $1 \%$ paraformaldehyde (PFA) in phosphate-buffered saline (PBS), incubated with DNase I (Sigma-Aldrich) and stained with antiBrdU-FITC antibody (Invitrogen). Analysis was performed using a FACSCanto II flow cytometer (BD Biosciences) and FlowJo software (TreeStar, Ashland, Oregon, USA).

\section{Evaluation of autoimmune tissue injury}

Spleens were frozen in liquid nitrogen and cut in $7 \mu \mathrm{m}$ sections. Slides were fixed in acetone at $4^{\circ} \mathrm{C}$ for $10 \mathrm{~min}$ at room temperature, placed in PBS for 5 min and blocked with $5 \%$ goat serum in PBS for $20 \mathrm{~min}$. The following primary antibodies were used for staining (all from BD): anti-mCD11c (clone HL3, 1:50), antimCD3e (clone 500A2, 1:50) and anti-mCD19 (clone1D3, 1:50). Secondary antibodies used for staining were (all from Invitrogen): Alexa Fluor 647 goat anti-rat IgG (1:200), Alexa Fluor 488 goat anti-hamster IgG (1:200) and streptavidin Alexa Fluor 555 conjugate (1:200). Sections were mounted with Vectashield containing 4',6-diamidino-2-phenylindole (DAPI). The slides were scanned using an Olympus BX 61 microscope and recorded via CellP software; the scans underwent digital morphometry using Adobe Photoshop. Lungs and kidneys from all mice were fixed in $10 \%$ buffered formalin, processed and embedded in paraffin. Two $\mu \mathrm{m}$ sections for periodic acid-Schiff (PAS) staining were prepared following routine protocols. The severity of the renal lesions was graded using the activity and chronicity indices for human lupus nephritis as described previously. ${ }^{31}$ Serum IL-12 levels were determined by ELISA following the manufacturer's protocol (OptEiA; BD Biosciences).

\section{Autoantibody analysis}

Serum antibody levels were determined by ELISA as described elsewhere. ${ }^{17}$

Anti-dsDNA antibodies: NUNC maxisorp ELISA plates were coated with poly-L-lysine (Trevigen, Gaithersburg, Maryland, USA) and mouse embryonic stem cell dsDNA. After incubation with mouse serum, dsDNA-specific IgG, $\operatorname{IgG}_{1}, \operatorname{IgG}_{2 \mathrm{a} / \mathrm{c}}, \operatorname{Ig}_{2 b}$, $\mathrm{IgG}_{3}$ and serum IgG levels were detected by ELISA (Bethyl Labs, Montgomery, Texas, USA).

Critidiae luciliae assay: 1:50 diluted serum was applied to fixed C luciliae slides (BioRad Laboratories, Redmond, Washington, USA). Binding to C luciliae kinetoplast was detected with FITC-conjugated goat anti-mIgG (1:1000, Invitrogen, Eugene, Oregon USA). DAPI staining (Vector Laboratories, Burlingame, California, USA) allowed co-localisation with kinetoplast dsDNA. For quantitation of kinetoplast staining intensity a semiquantitative score from 0 to 3 was used.

Anti-Sm: NUNC maxisorp ELISA plates were coated with Smith (Sm) antigen (Immunovision, Springdale, Arkansas, USA). The Sm IgG (Y12) antibody (GeneTex, San Antonio, Texas, USA) was used for standard. A horseradish peroxidaseconjugated goat anti-mouse IgG (Rockland, Gilbertsville, Pennsylvania, USA) was used for detection. The same 
procedure was followed for anti-SmRNP, anti-nucleosome and anti-Sm but ELISA plates were coated with Sm-RNP (Immunovision) or nucleosomes (USB Corporation, Cleveland, hio USA), respectively.
Rheumatoid factor: ELISA plates were coated with $10 \mu \mathrm{g} / \mathrm{ml}$ rabbit IgG (Jackson Immunoresearch, West Grove, Pennsylvania, USA) overnight at $4^{\circ} \mathrm{C}$. Serum samples were diluted 1:100; C57BL/6 10-week mouse serum was used as negative control.

A
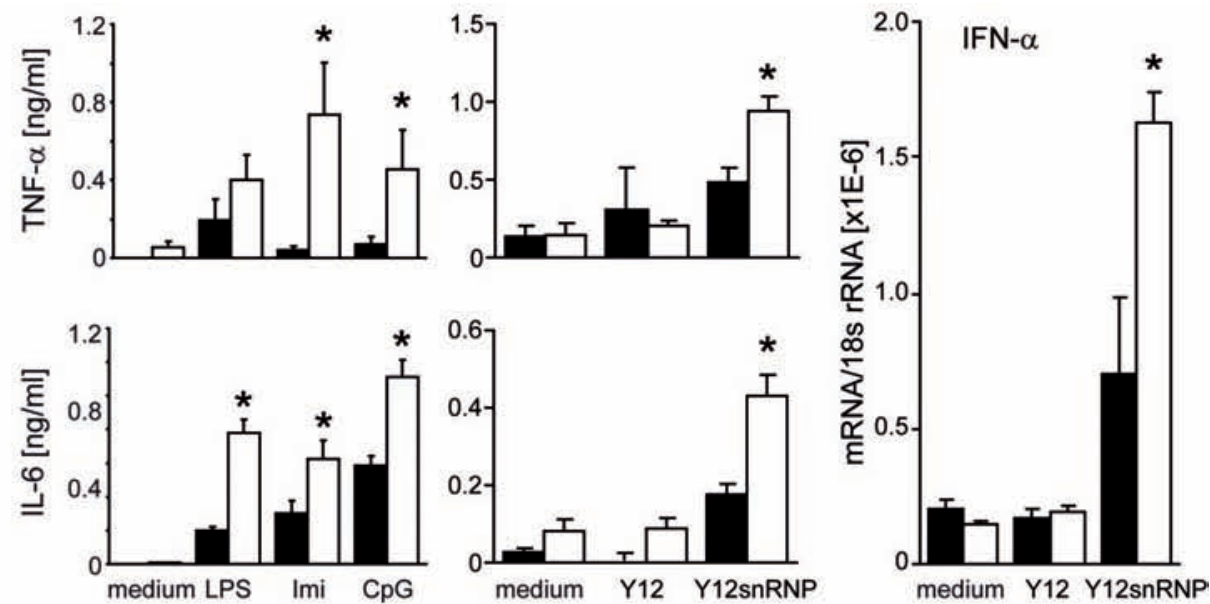

B

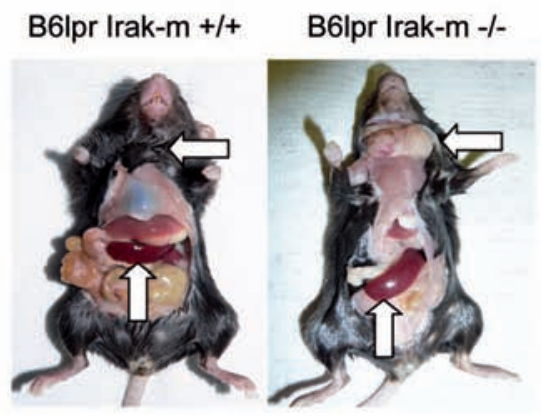

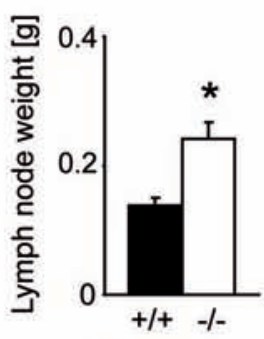

B6Ipr Irak-m

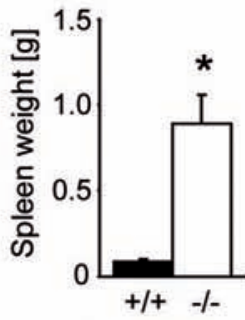

B6Ipr Irak-m

C

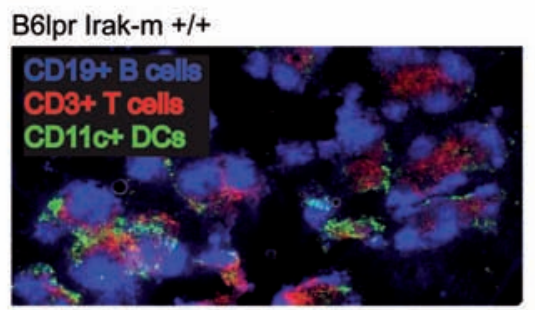

B6lpr Irak-m -/-
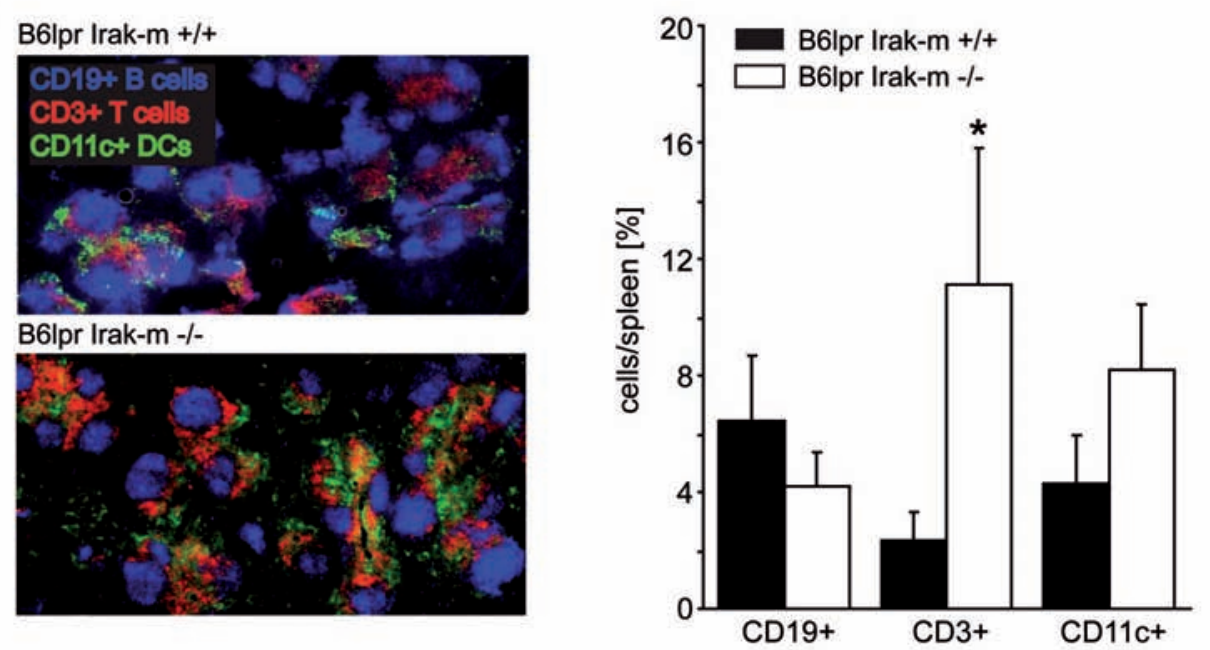

Figure 1 IRAK-M suppresses TLR7 and TLR9 signalling and lymphoproliferation in B6/pr mice. (A) Spleen monocytes were prepared from wildtype mice (black bars) or Irak-m-deficient mice (white bars) and stimulated with $1 \mu \mathrm{g} / \mathrm{ml}$ of lipopolysaccharide (LPS), imiquimod (Imi), CpG-DNA (CpG) or Y12-snRNP immune complexes as described in the Methods section. Supernatants were harvested after $24 \mathrm{~h}$ of stimulation and tumour necrosis factor $\alpha$ (TNF $\alpha$ ) and interleukin (IL)-6 release were determined by ELISA. For immune complex stimulation, interferon $\alpha$ (IFN $\alpha$ ) mRNA expression was determined by RT-PCR. Data represent mean \pm SEM from three independent experiments; * $p<0.05$ vs wild-type. (B) At 6 months of age, Irak-m-deficient B6 ${ }^{1 p r}$ mice showed splenomegaly (vertical arrows) and hyperplasia of cervical lymph nodes (horizontal arrows) compared with age-matched $\mathrm{B} 6^{/ p r}$ control mice. Quantitative data on the right show weight of mesenterial lymph nodes and spleens. Data represent mean $\pm S E M$ from at least 12 mice in each group; ${ }^{*} p<0.05$. (C) Immunofluorescence staining of spleen sections from 6-month-old B6/pr/lrak-m-/- and B6/pr wild-type mice. Representative images are shown at an original magnification of $\times 100$. Lack of IRAK-M is associated with an expansion of CD3+ T cells (red) and CD11c+ dendritic cells (green) but not of CD19+ B cells (blue). Quantitative data based on immunofluorescence staining on the right represent mean \pm SEM from at least 12 mice in each group; ${ }^{*} \mathrm{p}<0.05$. 
HRP-conjugated anti-mouse IgG was used as a secondary antibody.

\section{Real-time quantitative (TaqMan) RT-PCR}

Real-time (RT)-PCR was performed on mRNA from cells purified from spleen by two-step magnetic cell sorting (Miltenyi Biotec) as previously described. ${ }^{17}$ The SYBR Green Dye detection system was used for quantitative RT-PCR on Light Cycler 480 (Roche, Mannheim, Germany). Gene-specific primers (300 nM; Metabion, Martinsried, Germany) were used (see table 2 in online supplement). Controls consisting of $\mathrm{ddH}_{2} \mathrm{O}$ were negative for target and housekeeper genes.

\section{Statistical analysis}

One-way ANOVA followed by a post hoc Bonferroni test was used for multiple comparisons using GraphPad Prism Version 4.03. Single groups were compared by the unpaired two-tailed Student $t$ test. Data were expressed as mean \pm SEM. Survival curves were compared by Kaplan-Meier analysis using logrank two-tailed testing. Statistical significance was assumed at $\mathrm{p}<0.05$.

\section{RESULTS}

\section{IRAK-M suppresses TLR7 and TLR9 signalling}

IRAK-M is known to suppress TLR4 signalling at the kinase level, ${ }^{21}$ which is shared by other TLRs. ${ }^{32}$ We therefore hypothesised that IRAK-M would also suppress TLR7 and TLR9 signalling. Spleen monocytes were prepared from wild-type and Irak-m-deficient mice and stimulated with the TLR4 agonist LPS, the TLR7 agonist imiquimod and the TLR9 agonist CpGDNA, or with immune complexes (Y12snRNP). All three TLR agonists induced the production of TNF $\alpha$, IL- 6 and expression of interferon $\alpha$ (IFN $\alpha$ ) within $24 \mathrm{~h}$ in wild-type splenocytes, but Irak-m-deficient cells produced much more of these cytokines (figure 1A). Thus, IRAK-M suppresses TLR7 and TLR9 signalling in addition to TLR4 signalling.

\section{IRAK-M is induced in spleens and suppresses Iymphoproliferation in $\mathrm{B6}^{\text {/pr }}$ mice.}

We first carefully evaluated Irak-m-deficient B6 mice for signs of spontaneous autoimmunity but found no difference in lupus autoantibodies, serum cytokines and spleen immune cell numbers or state of activation from wild-type B6 mice up to 12 months of age (see table 1 in online supplement). Next we generated Irak-m-deficient $\mathrm{B}^{\mathrm{pr}}$ mice. The phenotype of homozygous B6 mice is introduced only by a single lupus susceptibility gene (lpr) which impairs Fas-induced apoptosis of autoreactive $\mathrm{B}$ and $\mathrm{T}$ cells. ${ }^{8}$ Because $\mathrm{B} 6^{\mathrm{lpr}}$ mice produce antinuclear autoantibodies and minor immune complex glomerulonephritis only late in life, litters of B $6^{\text {lpr/Irak-m- } /-}$ mice could be

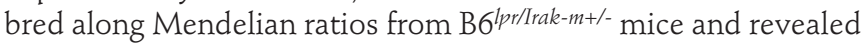
no weight gain differences compared with B6 mice (data not shown). For SLE phenotype analysis we first evaluated IRAK-M mRNA expression in spleens of B6 ${ }^{\text {pr }}$ mice and found IRAK-M mRNA to be increasingly expressed over time (data not shown). Next we compared the size of spleens and lymph nodes in 6-month-old B6 $6^{\text {pr }}$ and B6 Ipr/Irak-m-/- mice. The spleens and lymph nodes were significantly enlarged in B6 1 pr/lrak-m-/- mice compared with $\mathrm{B} 6^{\mathrm{pr}}$ mice (figure $1 \mathrm{~B}$ ). This was evident from spleen and bulk lymph node weights. Spleen histomorphology in 6-monthold mice showed that B6/pr/rak-m-/ mice had lymph follicle hyperplasia with an expansion of $\mathrm{T}$ cell and CD11c+ dendritic cell areas while CD19+ B cell areas were similar to those of B6r mice, also evidenced by a quantitative assessment of stained spleen scans (figure 1C). Thus, lack of IRAK-M accelerates lymphoproliferation in mice when introduced in the context of a single additional lupus susceptibility gene (lpr).

\section{IRAK-M suppresses the activation of dendritic cells in B6 $^{\text {Ipr }}$ mice}

IRAK-M modulates pathogen recognition in monocyte/ macrophages, ${ }^{21} 23$ so we hypothesised that IRAK-M may modulate the activation of dendritic cells in B6 ${ }^{\text {pr }}$ mice, cells that handle lupus autoantigens and regulate the expansion of autoreactive lymphocytes in SLE. Flow cytometry was performed to quantify and characterise the activation state of CD11c+ cells without additional stimuli directly after the spleen harvest at 6 months of age. CD11c+ and CD8+CD11c+ but not CD4+CD11+ cells were significantly more in total number as well as positive for the activation marker CD40 or MHCII in Irak-m-deficient B6 ${ }^{\text {pr }}$ mice (figure 2A). This was associated with increased mRNA levels of IL- 6 and IL-12 and with the IFN $\alpha$-dependent genes Mx1, Ifit1, TLR7 and TLR9 in the $\mathrm{CD} 11 \mathrm{~b}+$ splenocyte population (figure $2 \mathrm{~B}$ ). By contrast, IfN $\beta$ mRNA was not detectable in Irak-m-deficient B6lpr mice (not shown). Plasma cell differentiation and survival factors Baff/ $\mathrm{BlyS}$ and $\mathrm{Bcl} 2^{33}$ were also induced in Irak-m-deficient CD11b+ splenocytes (figure 2B). Consistent with increased dendritic cell activation, B6 lpr/Irak-m-/ mice had higher serum levels of IL-12 than B6 lpr mice (figure 2C). Thus, in autoimmune B6 ${ }^{\mathrm{lpr}}$ mice, IRAK-M suppresses dendritic cell activation-that is, their production of proinflammatory cytokines and factors that promote the differentiation of B cells into plasma cells and plasma cell survival.

\section{IRAK-M suppresses T cell expansion and stabilises the potential of regulatory $T$ cells to suppress $T$ cells in $\mathrm{B6}^{\text {pr }}$ mice}

Given its impact on dendritic cell activation, lack of IRAK-M might affect $\mathrm{T}$ cell populations in $\mathrm{B} 6^{\mathrm{lpr}}$ mice. Consistent with the expansion of spleen $\mathrm{T}$ cell areas (figure $1 \mathrm{~B}$ ), the numbers of CD4+ and CD8+ T cells, CD4/CD8 double negative 'autoreactive' $\mathrm{T}$ cells and CD4+/CD25+/Foxp3 'regulatory' $\mathrm{T}$ cells were all increased in the spleens of Irak-m-deficient B6 ${ }^{\text {pr }}$ mice and expressed higher levels of the activation marker CD69 (figure 3A). The latter was consistent with increased FoxP3 mRNA expression in CD4/CD25+ T cells (figure 3B). IRAK-M deficiency-associated expansion of CD4 $\mathrm{T}$ cells did not affect the Th1/Th2 balance as the mRNA expression of Th1 markers (T-bet/IFN $\gamma$ ) and Th2 markers (GATA3/IL-4) were consis-

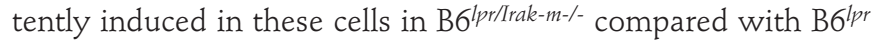
mice (figure 3B). Th17 cells and IL-17 mRNA expression were undetectable in mice of both genotypes. How does the expansion of Tregs affect T cell proliferation in Irak-m-deficient B6lpr mice? To answer this question we performed a $T$ cell suppression assay by co-culturing CD4+CD25+, CD4+CD25 neg and APC derived from spleens of either lpr or Irak-m-deficient B $6 \mathrm{lpr}$ mice. In both strains the same proportion of CD4+CD25+ cells stained positive for FoxP3 (data not shown). Interestingly, however, a significantly decreased level of Treg-induced suppression was observed in cells derived from Irak-m-deficient B6lpr mice (data not shown). To determine whether the loss of suppression is due to non-functional Tregs in Irak-m-deficient B6lpr mice, we co-cultured Tregs derived from this strain with wild-type APC. Strikingly, Irak-m-deficient Tregs showed clearly reduced suppression even in co-culture with wild-type APC or vice versa, 


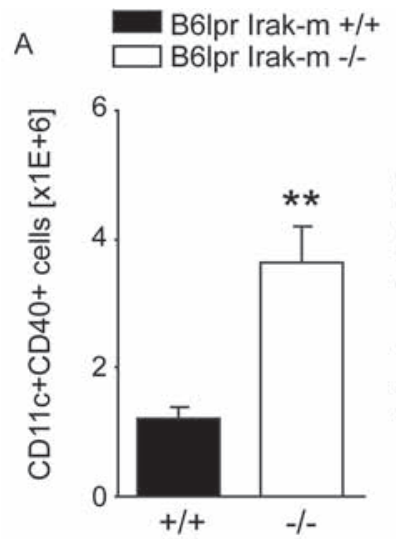

B6lpr Irak-m

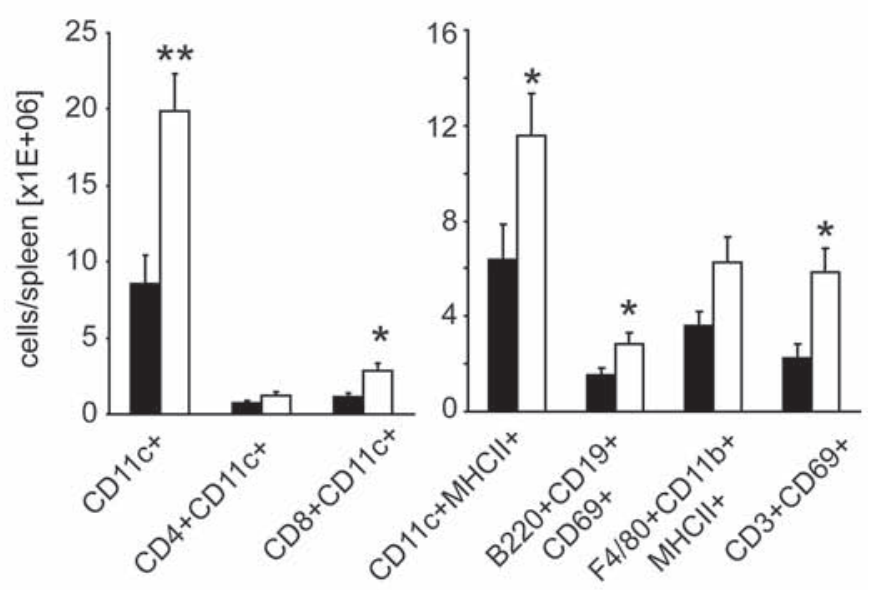

B

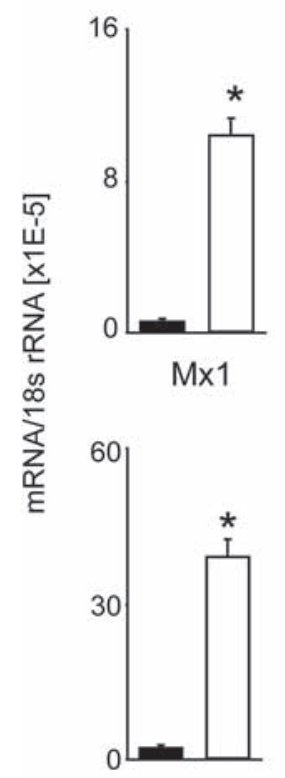

$\mathrm{Bcl}-2$

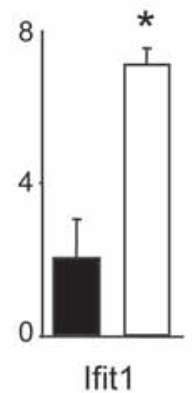

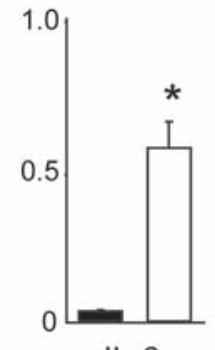

IL-6
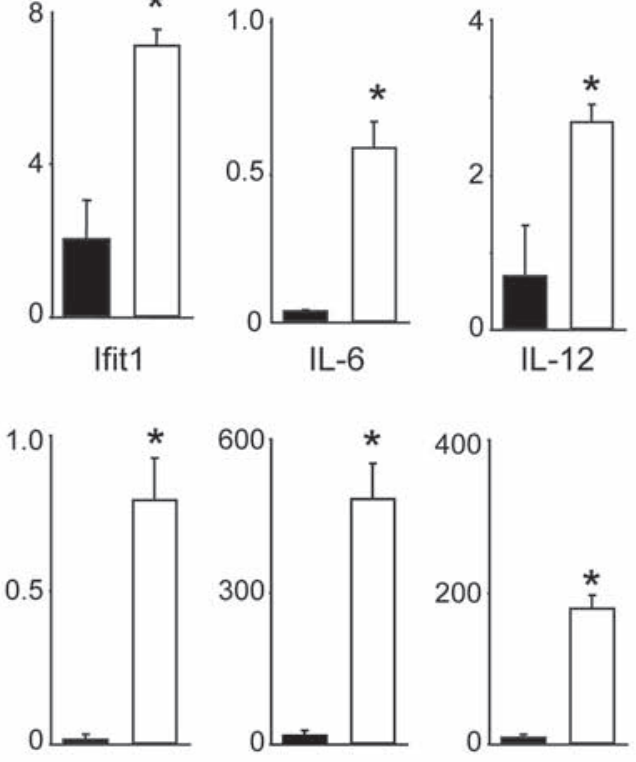

Baff

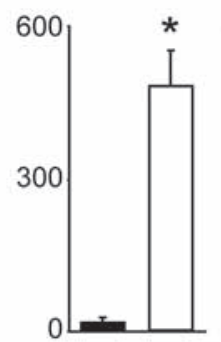

TLR7

C

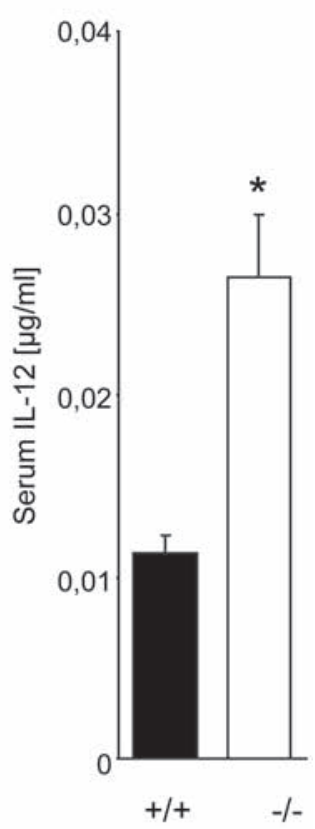

B6Ipr Irak-m

Figure 2 IRAK-M and dendritic cell activation in B6 $6^{\text {pr }}$ mice. (A) Spleen CD11c+ and dendritic cell subsets were quantified in B6 $6^{/ p r / / r a k-m-/-}$ and B6 $6^{/ p r}$ wild-type mice by flow cytometry using diverse expression markers as described in the Methods section. Data represent mean $\pm S E M$ from 10 mice

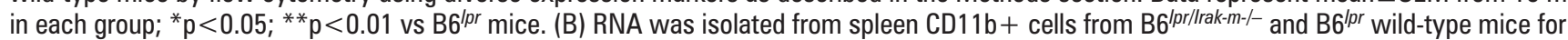
real-time PCR analysis. Data are expressed as means of the ratio of the specific mRNA versus that of $18 S$ rRNA $\pm S E M$; ${ }^{*} p<0.01$ vs $B 6^{l p r}$ mice. (C) Serum samples from 6-month-old B6/ ${ }^{/ p r / / r a k-m-/-}$ and $B 6^{/ p r}$ wild-type mice were analysed for IL-12p40 by ELISA. Data are mean \pm SEM from at least seven mice in each group; ${ }^{*} \mathrm{p}<0.05 \mathrm{vs} \mathrm{B} 6^{/ p r}$ mice.

indicating a contribution of IRAK-M from both cell types (figure 3C), which suggests that Tregs are dysfunctional in Irak-mdeficient $\mathrm{B} 6^{\text {Ipr }}$ mice. Together, IRAK-M suppresses the expansion of all $\mathrm{T}$ cells including the CD4/CD8 double negative autoreactive $T$ cells and stabilises the potential of Tregs to suppress $T$ cell proliferation in $\mathrm{B} 6^{\text {lpr }}$ mice.

\section{IRAK-M suppresses the expansion of plasma cells and} subsequent lupus autoantibody production in $\mathrm{B}^{\mathrm{ppr}}$ mice

Flow cytometry did not reveal any difference in numbers of mature B cells, follicular B cells and marginal zone B cells in spleens (figure 3D), which was consistent with the comparable size of $\mathrm{CD} 19+\mathrm{B}$ cell areas in spleens of $\mathrm{B} 6^{\text {lpr }}$ and $\mathrm{B} 6^{\text {lpr }}$
Irak-m-/- mice (figure 1B). However, Irak-m-deficient CD19+ B cells expressed higher levels of Bcl6 and Blimp1 mRNA (data not shown), two dedicated plasma cell differentiation and survival factors. ${ }^{33}$ These-as well as the increased levels of Baff/ BlyS and Bcl2 expressed by CD11b+ cells (figure 2B)-were consistent with increased numbers of plasma cells in spleens of Irak-m-deficient B6 mice (figure 3D). To see whether enhanced activation of dendritic cells and the expansion of $T$ cells and plasma cells affect IgG and lupus autoantibody production, we collected serum samples at monthly intervals from mice of both genotypes and determined antibody levels by ELISA. Irak-m-deficient $\mathrm{B} 6^{\text {lpr }}$ mice developed more hypergammaglobulinaemia than $\mathrm{B} 6^{\mathrm{lpr}}$ wild-type mice, which was not significant 
A
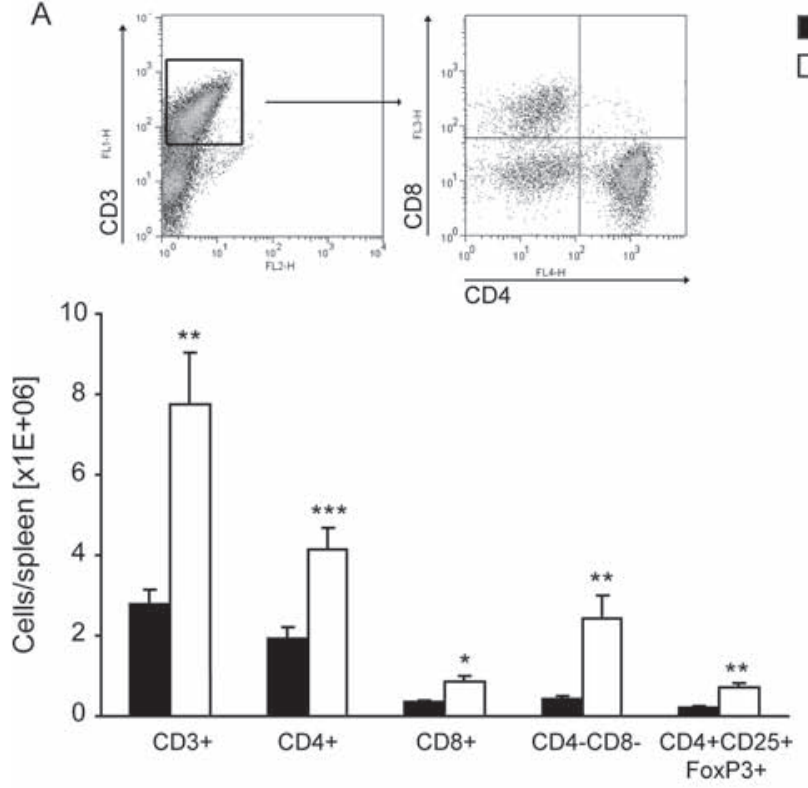

B6lpr Irak-m +/+ $\square$ B6lpr Irak-m -I-
B

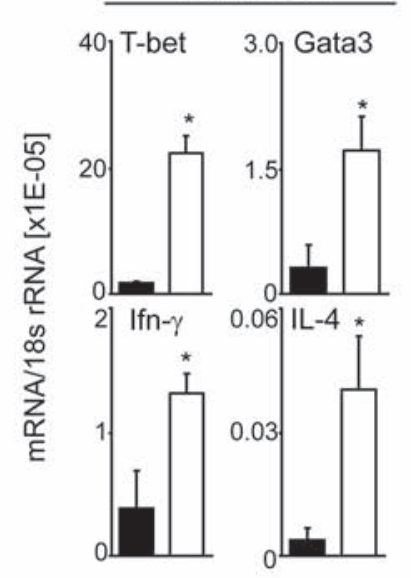

$\underline{\mathrm{CD} 4+\mathrm{CD} 25+}$

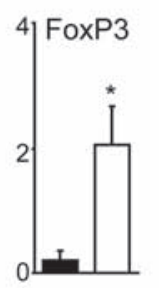

C

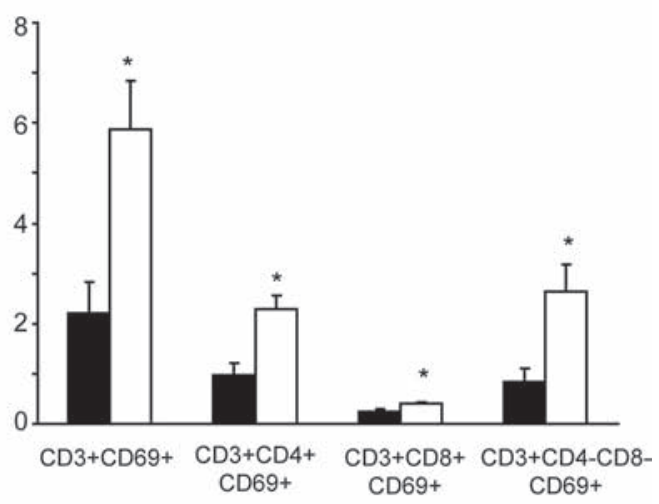

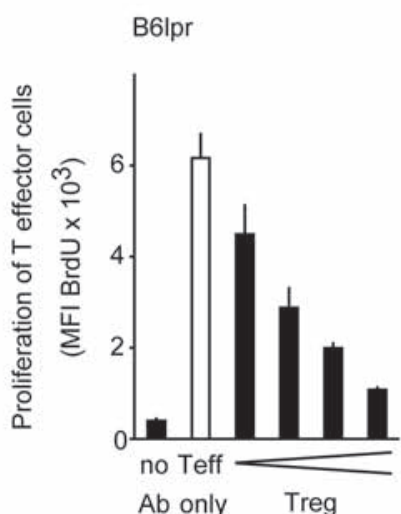

IRAK-M B6Ipr

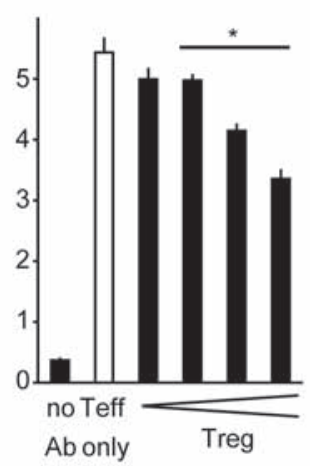

D

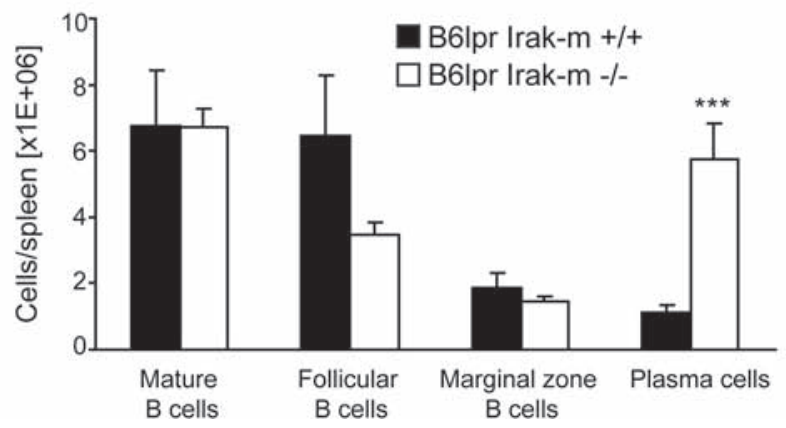

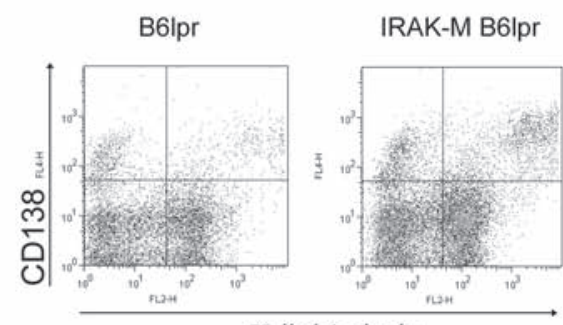

$\mathrm{K}$ light chain

Figure 3 IRAK-M and lymphocyte subsets in B6 $6^{\text {pr }}$ mice. (A) Flow cytometry was used to determine the total number of distinct T cell subsets in spleens of 6 -month-old $B 6^{/ p r / I r a k-m-~}-$ and $B 6^{/ p r}$ wild-type mice. The histogram shows mean $\pm S E M$ values of $8-14$ mice in each group; ${ }^{*} p<0.05$, ${ }^{* *} \mathrm{p}<0.01$, ${ }^{* *} \mathrm{p}<0.001$ vs B6 ${ }^{\text {pr }}$ mice. Representative FACS acquisition for T cells is shown. (B) Cellular mRNA was prepared from CD4+CD25and CD4+CD25 + spleen cell isolates from B6/pr//rak-m-/ and B6 $6^{\text {pr }}$ wild-type mice and analysed by real-time PCR. Data are expressed as means of the ratio of the specific mRNA versus that of $18 \mathrm{~S} r R N A \pm S E M ;{ }^{*} p<0.05$ vs B6/pr mice. (C) Splenocytes derived from B6/pr/lrak-m-/- and B6/pr mice were analysed for CD25 and FoxP3 expression by flow cytometry. CD4+CD25- T effector (Teff) cells, CD4+CD25+ T regulatory cells (Tregs) and antigen-presenting cells (APCs) were isolated from splenocytes of wild-type, B6 ${ }^{/ p r}$ or B6/pr/lrakm-/- mice. $7.5 \times 10^{4}$ Teff cells were stimulated with anti-CD3 antibody and cultured alone or together with increasing numbers of Tregs $\left(0.5,1,2\right.$ and $\left.4 \times 10^{4}\right)$ in the presence of $2 \times 10^{4}$ APCs. Proliferation of Teff cells was determined after 3 days by the incorporation of BrdU detected by flow cytometry. Diagrams show the mean fluorescence intensity of BrdU gated on CD4+FoxP3- cells. Error bars indicate SEM of $n=3$; ${ }^{*} p<0.01$ for Ipr vs IRAK-M/lpr at 1, 2 and $4 \times 10^{4}$ Tregs. (D) B cell subsets were determined by flow cytometry in spleens of 6 -month-old B6/pr/lrak-m- $/$ and B6 ${ }^{\text {pr }}$ wild-type mice $(B 220+\lg M+\lg D+$ mature $B$ cells; $\mathrm{B} 220+\mathrm{CD} 21^{\text {high }}$, $\mathrm{CD} 23^{\text {low }}$ marginal zone B cells; B220+CD21 low CD23 high follicular B cells; $\kappa$ light chain + CD138+ plasma cells). The histogram shows mean \pm SEM values of $8-14$ mice in each group; ${ }^{* *} p<0.001$ vs $B 6^{/ p r}$ mice. Representative FACS acquisition for plasma cells is shown. 
A

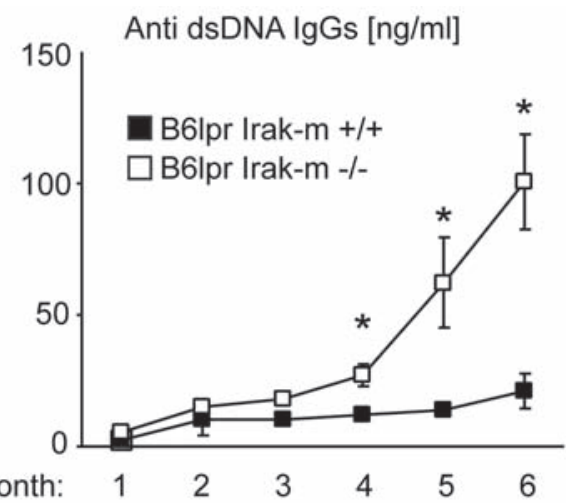

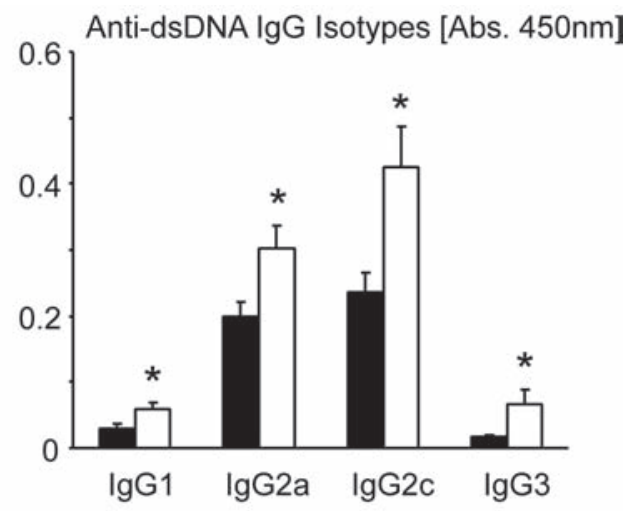

B

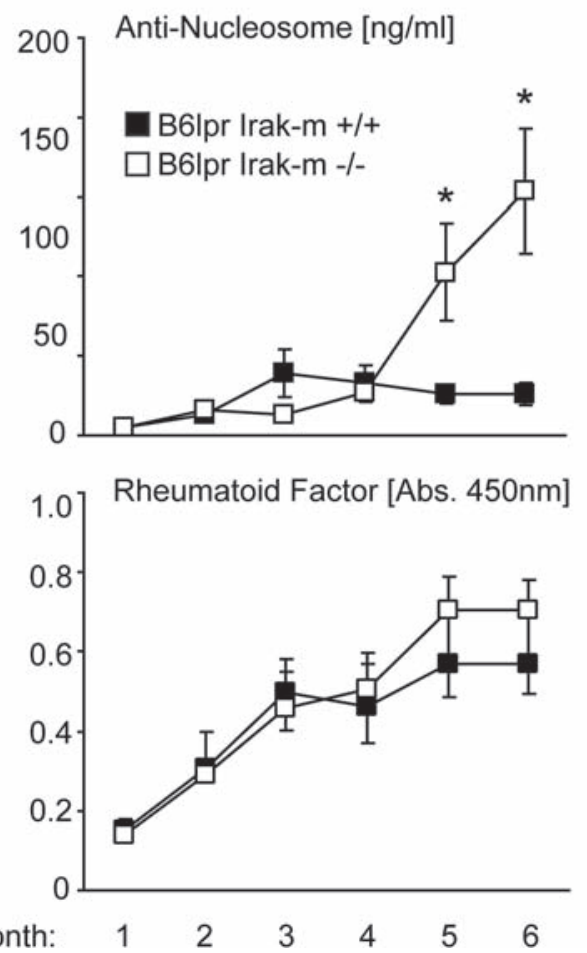

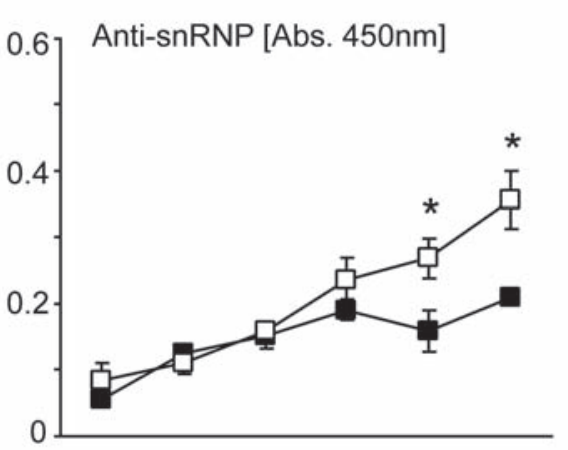

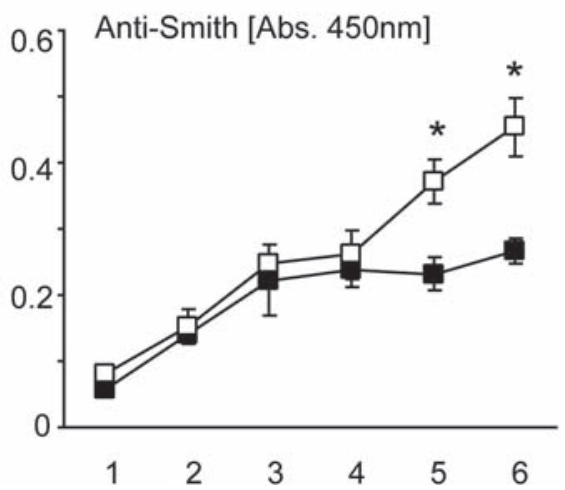

Figure 4 IRAK-M and serum IgG and DNA autoantibodies in B6 $6^{/ p r}$ mice. B6/pr/lrak-m-/- (white) and B6 $6^{/ p r}$ wild-type mice (black) were bled at monthly intervals to determine plasma levels of $(A) \lg G$ dsDNA autoantibodies and $(B)$ various lupus autoantibodies by ELISA. The isotype analysis of the total $\lg \mathrm{G}$ and anti-DNA IgG are from 6 months only. Data represent mean \pm SEM values from at least six mice at each time point and genotype; ${ }^{*} p<0.05$ vs $\mathrm{B}^{\prime p r}$ mice at the same time point.

before 6 months of age and mostly affected the $\operatorname{Ig}_{2 c}$ and $\operatorname{IgG}_{3}$ isotypes (data not shown). At that time, lack of IRAK-M had also increased the serum dsDNA autoantibody levels from all $\operatorname{IgG}$ isotypes (figure 4A). The specificity of dsDNA autoantibodies was confirmed by the Critidiae luciliae assay. Diluted serum from B6/pr/Irak-m-/- mice showed a much more intense binding to the dsDNA of the flagellate's kinetoplast than serum of $B 6^{l p r}$ mice. In addition, lack of IRAK-M was associated with increased production of anti-Sm IgG, anti-SnRNP IgG and anti-nucleosome IgG from 5 months of age compared with B6 ${ }^{\mathrm{pr}}$ mice (figure $4 \mathrm{~B}$ ). In contrast, rheumatoid factor levels were not affected by the Irak-m genotype (figure 4B). Lack of IRAK-M obviously accelerated autoantibody production of all isotypes, an effect that antedates the development of hypergammaglobulinaemia of only selected IgG isotypes by 1-2 months. Thus, IRAK-M preferentially suppresses the expansion of autoreactive plasma cells and the production of numerous autoantibodies against nuclear RNA and DNA autoantigens in $\mathrm{B}^{\mathrm{lpr}}$ mice.

IRAK-M protects $\mathrm{B}^{\text {Ipr }}$ mice from fatal autoimmune tissue injury SLE may be associated with little or even fatal autoimmune tissue injury, ${ }^{34}$ but $\mathrm{B} 6^{\text {lpr }}$ mice do not develop major tissue lesions and only mild glomerulonephritis from 6 months of age. ${ }^{8}$ Irak$m$-deficient $\mathrm{B}^{\mathrm{lpr}}$ mice had significant peribronchial mononuclear cell infiltrates and pneumonitis (figure $5 \mathrm{~A}$ ) and a semiquantitative lung injury score of $2.6 \pm 0.1$ for B6 $1 \mathrm{pr} / \mathrm{Irak}-\mathrm{m}-\mathrm{-}$ - mice compared with $0.3 \pm 0.2$ for $B 6^{\text {pr }}$ mice $(\mathrm{p}<0.0001)$. Furthermore, Irak- $m$ deficiency was associated with diffuse mesangioproliferative glomerulonephritis, as indicated by PAS-positive matrix expansion, glomerular hypercellularity and capillary obstruction (figure $5 \mathrm{~B}$ ). The composite activity score for lupus nephritis was $7.9 \pm 0.8$ in B $6^{\mathrm{pr} /}$ Irak-m- mice and $3.4 \pm 0.4$ in $B 6^{\text {lpr }}$ mice $(\mathrm{p}=0.003)$. The composite chronicity score was $1.4 \pm 0.2$ in B6 ${ }^{1 p r / I r a k-m-/-}$ mice and $0.0 \pm 0$ in B $6^{\text {pr }}$ 

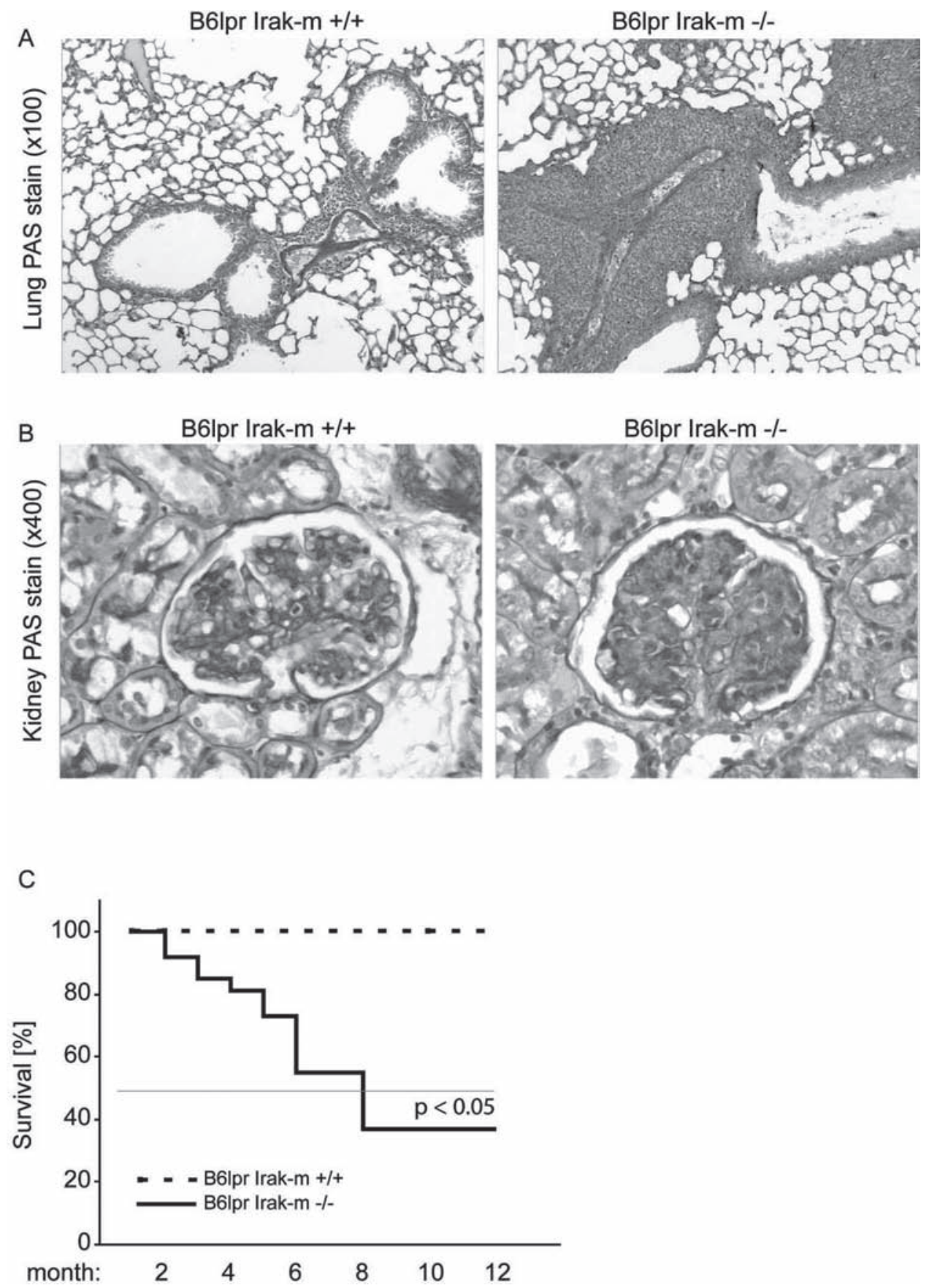

Figure 5 Lung injury, lupus nephritis and overall survival in B6 $6^{\text {pr }}$ mice. (A) Lung and (B) renal sections were stained with periodic acid-Schiff (PAS). Images are representative of at least 12 mice in each group. (C) Survival was studied in independent cohorts of mice and is illustrated as a KaplanMeier curve. Note that B6 $6^{/ p / / r a k-m-/-}$ mice (continuous line) reach $50 \%$ survival at 8 months of age while all B6 ${ }^{/ p r}$ wild-type mice (broken line) survived until 12 months of age.

mice ( $\mathrm{p}=0.0001)$. In Irak-m-deficient B6 ${ }^{\text {pr }}$ mice, increased glomerular damage was associated with increased glomerular positivity

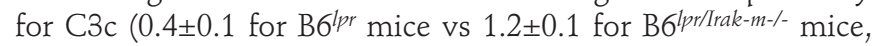
$\mathrm{p}=0.0005)$. Does the genotype-dependent autoimmune tissue injury affect the mortality of B $6^{\text {lpr }}$ mice? In Irak-m-deficient B $6^{\text {Ipr }}$ mice, $50 \%$ had died at 34 weeks of age while none of the $\mathrm{B} 6$ pr mice had died up to 52 weeks of age (figure 5C), suggesting that IRAK-M is a gene that protects B6lpr mice significantly from SLE and from SLE-related mortality Together, IRAK-M protects B6 $6^{\text {pr }}$ mice from systemic autoimmunity and also from fatal autoimmune tissue injury, mainly by suppressing the activation of APC and the expansion of autoreactive lymphocytes.

\section{IRAK-M suppresses autoimmunity by inhibiting TLR7 signalling in $\mathrm{B6}^{\mathrm{lpr}}$ mice}

The immunostimulatory effects of endogenous nucleic acids are known to drive SLE via TLR7. ${ }^{35} 36$ We therefore speculated that Irak-m deficiency aggravated murine lupus mainly by uncoupling TLR7 signalling. To test this concept we treated additional cohorts of B6 ${ }^{\text {pr }}$ and $\mathrm{B} 6^{\text {Ipr/Irak-m-/ }}$ mice with a TLR7 inhibitor. ${ }^{28}$ ${ }^{29}$ All mice were treated for 10 weeks and killed at 6 months of age. TLR7 blockade abrogated the accelerated kidney and lung disease in Irak-m-deficient B6 $6^{\text {lpr }}$ mice to the phenotype level of $\mathrm{B}^{\mathrm{lpr}}$ mice (figure 6A,B). Most strikingly, none of the Irak-mdeficient $\mathrm{B} 6^{\mathrm{lpr}}$ mice treated with TLR7 antagonist died during 
A

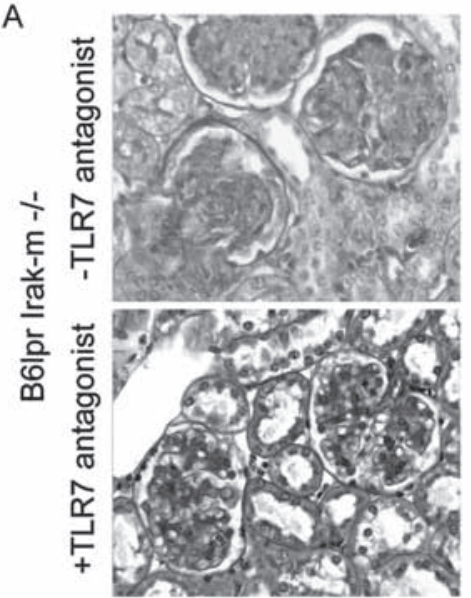

B

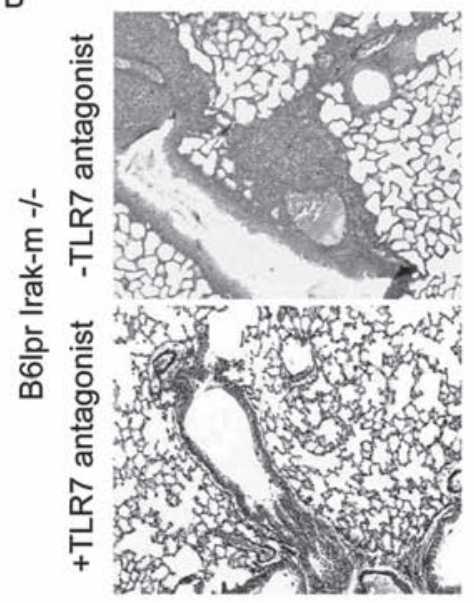

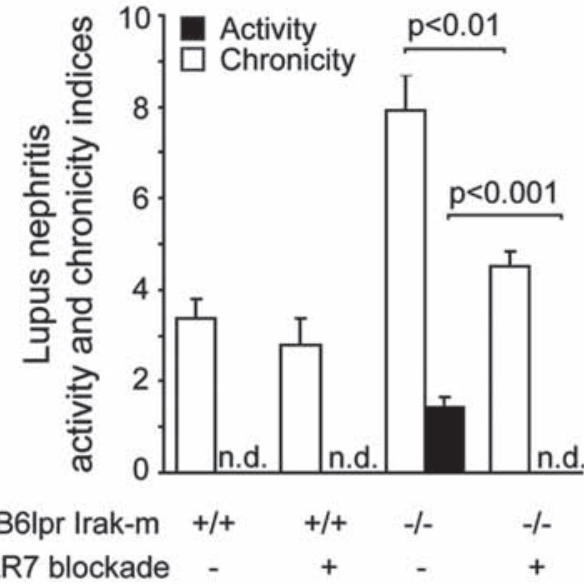

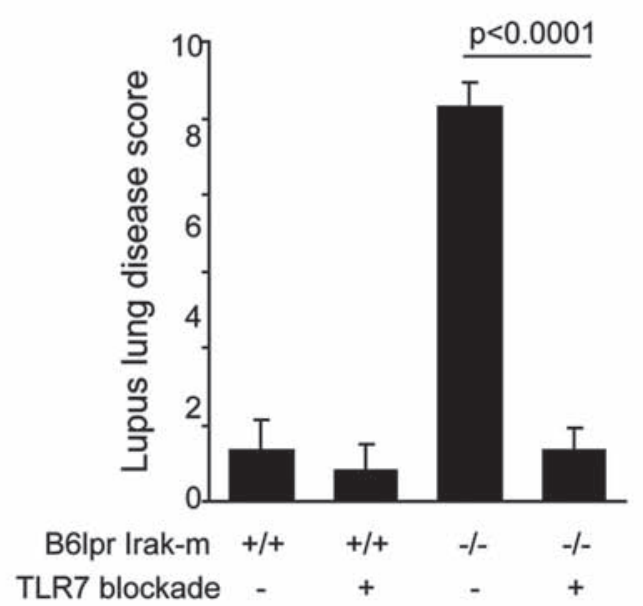

C

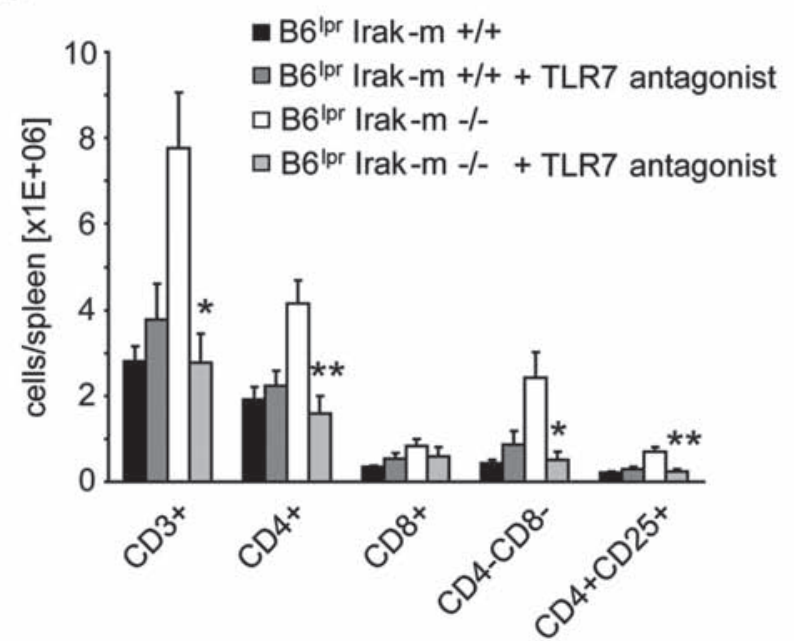

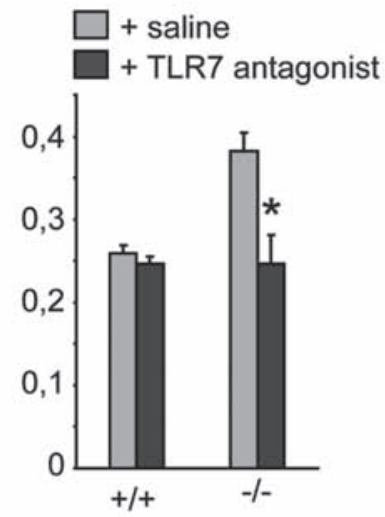

B6Ipr Irak-m

Anti-snRNP [Abs. $450 \mathrm{~nm}$ ]

Figure 6 TLR7 antagonism in B6/pr and B6/pr/rak-m-/- mice. (A) Kidney and (B) lung sections were stained with periodic acid-Schiff (PAS). Images are representative of six B6/pr//rak-m-/ mice in each group. The respective morphometric analyses for each organ from treated and untreated $B 6^{/ p r}$ and $\mathrm{B} 6^{\text {/pr/lrak-m-/- }}$ mice are shown below. Kidney morphometry was separately scored for disease activity (white bars) and chronicity (black bars) as described in the Methods section. Data are mean \pm SEM values. (C) Flow cytometry was used to determine the total number of distinct T cell subsets in spleens of 6-month-old B6 $/$ pr/lrak-m- $/-$ and B6 $6^{/ p r}$ wild-type mice that had been treated with the TLR7 antagonist. The histogram shows mean \pm SEM values of $6-14$ mice in each group; ${ }^{*} \mathrm{p}<0.05,{ }^{*} \mathrm{p}<0.01$ vs untreated Irak-m-deficient B6 ${ }^{\text {/pr }}$ mice. B6/pr/lrak-m-/- were bled at month 6 to determine plasma levels of anti-snRNP and autoantibodies by ELISA (right histogram). Data represent mean \pm SEM values of $6-14$ mice in each group; ${ }^{*} p<0.05$ vs untreated Irak-m-deficient B6 ${ }^{/ p r}$ mice. 
the study period; hence, TLR7 blockade prevented the premature lethality observed in Irak-m-deficient B6 $6^{\text {pr }}$ mice. In contrast, TLR7 antagonism had only a minor and non-significant effect on the mild SLE phenotype of B6 ${ }^{l p r}$ mice (figure 6). TLR7 blockade completely reversed the expansion of spleen $\mathrm{T}$ cells including the CD4/CD8-negative 'autoreactive' $\mathrm{T}$ cells (figure 6C). TLR7 blockade also reversed the increased levels of RNA (but not DNA) autoantibodies in Irak-m-deficient B6 ${ }^{\mathrm{pr}}$ mice (figure 6C, data not shown). We therefore conclude that Irak-m deficiency accelerates SLE in B6 ${ }^{\text {pr }}$ mice by fostering TLR7 signalling.

\section{DISCUSSION}

TLR7 signalling contributes to autoimmunity ${ }^{635}$ and IRAK-M suppresses TLR signalling, ${ }^{21}$ so we hypothesised that IRAK-M might suppress autoimmunity. Our data support the latter by two lines of evidence. First, Irak-m deficiency aggravates the autoimmune phenotype and mortality of B6 $6^{\text {pr }}$ mice. Second, TLR7 blockade almost entirely abrogates the aggravated autoimmune phenotype of Irak-m-deficient B6 ${ }^{\text {lpr }}$ mice.

We selected $\mathrm{B} 6^{\mathrm{lpr}}$ mice as an appropriate latent autoimmunity model because female B6 ${ }^{\text {pr }}$ mice develop some lupus autoantibodies but no major autoimmune tissue injuries. ${ }^{8}$ The selection of $\mathrm{lpr}$ mice on the C57BL/6 genetic background also allowed us to intercross them with Irak-m-deficient B6 mice to obtain and expand $\mathrm{B} 6$ pr/Irak-m-/- mice. Introducing Irak-m deficiency into B6 ${ }^{\text {pr }}$ mice introduced premature mortality in these mice by dramatically accelerating their autoimmune phenotype in terms of autoantibody production and autoimmune tissue injury, both of which were earlier in onset and more severe at a given time point. As Irak-m deficiency alone did not cause autoimmunity in B6 mice, IRAK-M instead acts as a modifier or enhancer gene together with the Ipr mutation. Obviously the Fas deficiency provided by the Ipr mutation is sufficient for loss of tolerance (ie, autoimmunity), but overt autoimmune disease requires at least another single genetic abnormality such as dysfunctional Irak-m in $\mathrm{B} 6^{\mathrm{pr}}$ mice. These data are in line with studies that introduced Tlr9 or Sigirr deficiency into B6 ${ }^{l p r}$ mice. ${ }^{16} 17$ It is noteworthy that Tlr9 or Sigirr deficiency both accelerate autoimmunity in lupus mice by enhancing TLR7 signalling in APC. ${ }^{17} 3637$ For SIGIRR, these findings were also validated in pristane-induced lupus of B6 mice. ${ }^{38}$ TLR7 signalling was recently found to contribute significantly to lupus-like autoimmunity because ribonucleoproteins such as U1snRNP act as endogenous TLR7 agonists and activate dendritic cells and B cells such as viral RNA. ${ }^{39-41}$ As such, TLR7 signalling induces type I interferons and interferonstimulated genes and enhances autoantigen presentation which fosters autoantigen-directed $\mathrm{T}$ and $\mathrm{B}$ cell responses (ie, autoimmunity). ${ }^{6} 42$ Our comparative phenotype analysis of $\mathrm{B} 6^{\mathrm{pr}}$ and B6 lpr/lrak-m-1- mice showed that all of these aforementioned components were also associated with the B6/pr/lrak-m-/ genotype. Because TLR7 antagonism almost entirely prevented the aggravated autoimmune phenotype of B6 ${ }^{\mathrm{pr} / \mathrm{Irak}-\mathrm{m}-/}$ mice, we conclude that Irak-m deficiency accelerates autoimmunity by uncoupling TLR7 signalling. Only the increased DNA autoantibody production was TLR7-independent and should relate to enhanced TLR9 signalling. ${ }^{16}$ While the specificity of the TLR7 antagonist used in this study is under debate, ${ }^{43}$ its lack of modulating DNA autoantibodies adds to the evidence for its specificity by in vitro testing. ${ }^{28}$ IRAK-M has been shown to suppress TLR4 signalling by preventing the dissociation of IRAK1 and IRAK4 from the TLR MyD88 signalling complex as an essential element of the TLR downstream signalling cascade towards the activation of MAP

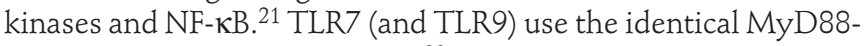
dependent signalling pathway, ${ }^{32}$ which is consistent with our finding that Irak-m-deficient spleen monocytes display increased TNF $\alpha$ or IL-6 production on stimulation with TLR4, TLR7 or TLR9 agonists or other studies that observed increased TLR2 and TLR7 signalling on Irak-m silencing in RAM macrophages. ${ }^{44}$ A suppressive role of IRAK-M on autoimmune tissue injury is also anticipated by a recent study that found IRAK-M induction to be associated with repeated TLR7 agonist exposure which ultimately suppressed experimental allergic encephalomyelitis in mice. ${ }^{45}$

In summary, lack of IRAK-M accelerates autoimmunity and autoimmune tissue injury of B6 ${ }^{\mathrm{pr}}$ mice by enhancing TLR7dependent pathomechanisms. Suppression of autoimmunity is a previously unknown function of IRAK-M. We identified loss of function mutations in the IRAK-M gene that are previously unknown genetic risk factors for SLE and potentially also for other systemic autoimmune diseases.

Funding This work was supported by a grant from the Deutsche Forschungsgemeinschaft (AN372/10-1 and GRK 1202) to H-JA. CK was funded by the FöFoLe program of the Medical Faculty, University of Munich.

\section{Competing interests None.}

Provenance and peer review Not commissioned; externally peer reviewed.

\section{REFERENCES}

1. Goodnow CC. Multistep pathogenesis of autoimmune disease. Cell 2007;130:25-35.

2. Gregersen PK, Olsson LM. Recent advances in the genetics of autoimmune disease. Annu Rev Immunol 2009;27:363-91.

3. Kotzin BL. Systemic lupus erythematosus. Cell 1996;85:303-6.

4. Kanta H, Mohan C. Three checkpoints in lupus development: central tolerance in adaptive immunity, peripheral amplification by innate immunity and end-organ inflammation. Genes Immun 2009;10:390-6.

5. Theofilopoulos AN, Baccala R, Beutler B, et al. Type I interferons (alpha/beta) in immunity and autoimmunity. Annu Rev Immunol 2005;23:307-36.

6. Marshak-Rothstein A, Rifkin IR. Immunologically active autoantigens: the role of toll-like receptors in the development of chronic inflammatory disease. Annu Rev Immunol 2007;25:419-41.

7. Hom G, Graham RR, Modrek B, et al. Association of systemic lupus erythematosus with C8orf13-BLK and ITGAM-ITGAX. N Engl J Med 2008;358:900-9.

8. Cohen PL, Eisenberg RA. Lpr and gld: single gene models of systemic autoimmunity and lymphoproliferative disease. Annu Rev Immunol 1991;9:243-69.

9. Botto M, Dell'Agnola C, Bygrave AE, et al. Homozygous C1q deficiency causes glomerulonephritis associated with multiple apoptotic bodies. Nat Genet 1998;19:56-9.

10. Manderson AP, Botto M, Walport MJ. The role of complement in the development of systemic lupus erythematosus. Annu Rev Immunol 2004;22:431-56.

11. Napirei M, Karsunky $\mathrm{H}$, Zevnik B, et al. Features of systemic lupus erythematosus in Dnase1-deficient mice. Nat Genet 2000;25:177-81.

12. Shull MM, Ormsby I, Kier AB, et al. Targeted disruption of the mouse transforming growth factor-beta 1 gene results in multifocal inflammatory disease. Nature 1992;359:693-9

13. Hibbs ML, Tarlinton DM, Armes J, et al. Multiple defects in the immune system of Lyn-deficient mice, culminating in autoimmune disease. Cell 1995;83:301-11.

14. Mohan C, Alas E, Morel L, et al. Genetic dissection of SLE pathogenesis. Sle1 on murine chromosome 1 leads to a selective loss of tolerance to H2A/H2B/DNA subnucleosomes. J Clin Invest 1998;101:1362-72.

15. Subramanian S, Tus K, Li OZ, et al. A TIr7 translocation accelerates systemic autoimmunity in murine lupus. Proc Natl Acad Sci USA 2006;103:9970-5.

16. Lartigue A, Courville P, Auquit I, et al. Role of TLR9 in anti-nucleosome and anti-DNA antibody production in Ipr mutation-induced murine lupus. J Immunol 2006;177:1349-54

17. Lech M, Kulkarni OP, Pfeiffer S, et al. Tir8/Sigirr prevents murine lupus by suppressing the immunostimulatory effects of lupus autoantigens. J Exp Med 2008;205:1879-88.

18. Shimizu S, Sugiyama N, Masutani K, et al. Membranous glomerulonephritis development with Th2-type immune deviations in MRL/lpr mice deficient for IL-27 receptor (WSX-1). J Immunol 2005;175:7185-92.

19. Yin Z, Bahtiyar G, Zhang N, et al. IL-10 regulates murine lupus. J Immunol 2002;169:2148-55.

20. Suzuki N, Suzuki S, Duncan GS, et al. Severe impairment of interleukin-1 and Toll-like receptor signalling in mice lacking IRAK-4. Nature 2002;416:750-6.

21. Kobayashi K, Hernandez LD, Galán JE, et al. IRAK-M is a negative regulator of Tolllike receptor signaling. Cell 2002;110:191-202.

22. van 't Veer $\mathbf{C}$, van den Pangaart PS, van Zoelen MA, et al. Induction of IRAK-M is associated with lipopolysaccharide tolerance in a human endotoxemia model. J Immunol 2007; 179:7110-20. 
23. Deng JC, Cheng G, Newstead MW, et al. Sepsis-induced suppression of lung innate immunity is mediated by IRAK-M. J Clin Invest 2006;116:2532-42.

24. del Fresno C, Otero K, Gómez-García L, et al. Tumor cells deactivate human monocytes by up-regulating IL-1 receptor associated kinase-M expression via CD44 and TLR4. J Immunol 2005;174:3032-40.

25. Seki M, Kohno S, Newstead MW, et al. Critical role of IL-1 receptor-associated kinase-M in regulating chemokine-dependent deleterious inflammation in murine influenza pneumonia. J Immunol 2010;184:1410-18.

26. Li H, Cuartas E, Cui W, et al. IL-1 receptor-associated kinase M is a central regulator of osteoclast differentiation and activation. J Exp Med 2005;201:1169-77.

27. Balaci L, Spada MC, Olla N, et al. IRAK-M is involved in the pathogenesis of earlyonset persistent asthma. Am J Hum Genet 2007;80:1103-14.

28. Pawar RD, Ramanjaneyulu A, Kulkarni OP, et al. Inhibition of Toll-like receptor-7 (TLR-7) or TLR-7 plus TLR-9 attenuates glomerulonephritis and lung injury in experimental lupus. J Am Soc Nephrol 2007;18:1721-31.

29. Barrat FJ, Meeker T, Gregorio J, et al. Nucleic acids of mammalian origin can act as endogenous ligands for Toll-like receptors and may promote systemic lupus erythematosus. J Exp Med 2005;202:1131-9.

30. Anz D, Koelzer VH, Moder S, et al. Immunostimulatory RNA blocks suppression by regulatory T cells. J Immunol 2010;184:939-46.

31. Patole PS, Pawar RD, Lech M, et al. Expression and regulation of Toll-like receptors in lupus-like immune complex glomerulonephritis of MRL-Fas(Ipr) mice. Nephrol Dial Transplant 2006;21:3062-73.

32. Takeuchi 0, Akira S. Pattern recognition receptors and inflammation. Cell 2010;140:805-20.

33. Mackay F, Schneider P. Cracking the BAFF code. Nat Rev Immunol 2009;9:491-502.

34. Rahman A, Isenberg DA. Systemic lupus erythematosus. N Engl J Med 2008; 358:929-39.
35. Anders $\mathbf{H J}$, Krug A, Pawar RD. Molecular mimicry in innate immunity? The viral RNA recognition receptor TLR7 accelerates murine lupus. Eur J Immunol 2008:38:1795-9.

36. Santiago-Raber ML, Dunand-Sauthier I, Wu T, et al. Critical role of TLR7 in the acceleration of systemic lupus erythematosus in TLR9-deficient mice. J Autoimmun 2010;34:339-48.

37. Nickerson KM, Christensen SR, Shupe J, et al. TLR9 regulates TLR7- and MyD88dependent autoantibody production and disease in a murine model of lupus. $\mathrm{J}$ Immunol 2010;184:1840-8.

38. Lech M, Skuginna V, Kulkarni OP, et al. Lack of SIGIRR/TIR8 aggravates hydrocarbon oil-induced lupus nephritis. J Pathol 2010;220:596-607.

39. Savarese E, Chae OW, Trowitzsch S, et al. U1 small nuclear ribonucleoprotein immune complexes induce type I interferon in plasmacytoid dendritic cells through TLR7. Blood 2006:107:3229-34.

40. Diebold SS, Kaisho T, Hemmi H, et al. Innate antiviral responses by means of TLR7mediated recognition of single-stranded RNA. Science 2004;303:1529-31.

41. Heil F, Hemmi H, Hochrein $\mathrm{H}$, et al. Species-specific recognition of single-stranded RNA via toll-like receptor 7 and 8. Science 2004;303:1526-9.

42. Anders HJ. Pseudoviral immunity - a novel concept for lupus. Trends Mol Med 2009;15:553-61.

43. Lenert PS. Classification, mechanisms of action, and therapeutic applications of inhibitory oligonucleotides for Toll-like receptors (TLR) 7 and 9. Mediators Inflamm 2010;2010:986596

44. Hassan F, Islam S, Tumurkhuu G, et al. Involvement of interleukin-1 receptorassociated kinase (IRAK)-M in toll-like receptor (TLR) 7-mediated tolerance in RAW 264.7 macrophage-like cells. Cell Immunol 2009;256:99-103.

45. Hayashi T, Gray CS, Chan M, et al. Prevention of autoimmune disease by induction of tolerance to Toll-like receptor 7. Proc Natl Acad Sci USA 2009;106:2764-9. 


\section{A Interleukin-1 receptor-associated kinase-M suppresses systemic lupus erythematosus}

Maciej Lech, Claudia Kantner, Onkar P Kulkarni, Mi Ryu, Ekaterina

Vlasova, Jürgen Heesemann, David Anz, Stefan Endres, Koichi S

Kobayashi, Richard A Flavell, Javier Martin and Hans-Joachim Anders

Ann Rheum Dis 2011 70: 2207-2217 originally published online August 29, 2011

doi: 10.1136/ard.2011.155515

Updated information and services can be found at:

http://ard.bmj.com/content/70/12/2207

\section{Supplementary Material}

References

Email alerting service
Supplementary material can be found at:

http://ard.bmj.com/content/suppl/2011/07/22/ard.2011.155515.DC1.ht $\mathrm{ml}$

These include:

This article cites 45 articles, 18 of which you can access for free at: http://ard.bmj.com/content/70/12/2207\#BIBL

Receive free email alerts when new articles cite this article. Sign up in the box at the top right corner of the online article.

Collections

Articles on similar topics can be found in the following collections

Immunology (including allergy) (4368)

Connective tissue disease (3673)

Renal medicine (179)

Systemic lupus erythematosus (496)

\section{Notes}

To request permissions go to:

http://group.bmj.com/group/rights-licensing/permissions

To order reprints go to:

http://journals.bmj.com/cgi/reprintform

To subscribe to BMJ go to:

http://group.bmj.com/subscribe/ 